\title{
Molecular dynamics study of cristobalite silica using a charge transfer three-body potential: Phase transformation and structural disorder
}

\author{
Liping Huang \\ Department of Materials Science and Engineering, University of Illinois, Urbana, Illinois 61801 \\ John Kieffer ${ }^{\mathrm{a})}$ \\ Department of Materials Science and Engineering, University of Michigan, Ann Arbor, \\ Michigan 48109-2136
}

(Received 26 July 2002; accepted 23 October 2002)

\begin{abstract}
Structural and dynamic properties of cristobalite silica have been studied using molecular dynamics simulations based on a charge transfer three-body potential model. In this potential model, the directional covalent bonding of $\mathrm{SiO}_{2}$ is characterized by a charge transfer function of the interatomic distance between $\mathrm{Si}$ and $\mathrm{O}$ atoms, and in the form of $\mathrm{Si}-\mathrm{O}-\mathrm{Si}$ and $\mathrm{O}-\mathrm{Si}-\mathrm{O}$ three-body interactions. The dynamic properties such as infrared spectra and density of states at room and elevated temperatures are in excellent agreement with experiments, and are also consistent with the recently proposed rigid unit modes model. The $\alpha$ - and $\beta$-cristobalite crystallographic structures are well reproduced in this model, and the transition between these modifications occurs reversibly and reproducibly in simulations, both as a result of changes in pressure and temperature. The thermally induced transition results in a significantly more disordered $\beta$-cristobalite than the pressure-induced $\beta$-cristobalite at room temperature. While simulated $\alpha$-cristobalite exhibits a positive thermal expansion coefficient, it is almost zero for $\beta$-cristobalite up to $2000 \mathrm{~K}$ and slightly negative at higher temperatures, confirming results from recent $\mathrm{x}$-ray diffraction experiments and other simulations with potential models based on ab initio calculations. (C) 2003 American Institute of Physics.
\end{abstract}

[DOI: $10.1063 / 1.1529684]$

\section{INTRODUCTION}

In recent years, much attention has been paid to the mechanism of the structural transition between $\alpha$ - and $\beta$-cristobalite, and the structure of the $\beta$-cristobalite. ${ }^{1-20} \mathrm{Ex}-$ perimental evidence and theoretical analysis suggest that $\beta$-cristobalite does not occur in the ideal structure $F d \overline{3} m$ proposed by Wyckoff, ${ }^{21}$ and the structure may actually be dynamically disordered, ${ }^{4,7}, 10-13,18,20,22$ but the origin of the disorder is unclear and has long been a controversial subject. $\beta$-cristobalite could represent the dynamic average of small domains of $\alpha$-cristobalite, ${ }^{4,22}$ or the disorder arises from the existence of a large number of large-amplitude rigid unit modes (RUMs). ${ }^{7,10-13,18,20}$ Therefore, several approaches have been developed to predict the structure and properties of $\beta$-cristobalite as well as of other silica polymorphs. These approaches range from $a b$ initio quantum-mechanical calculations ${ }^{8,23,24}$ to those based on empirical interatomic potentials. $^{25-31}$

Teter et al. have correctly predicted the structures of $\alpha$-quartz, $\alpha$-cristobalite, and stishovite based on firstprinciples calculations. ${ }^{23}$ The structural change of $\alpha$-quartz under pressure and the structural properties of $\beta$-cristobalite have also been investigated using a similar approach. ${ }^{8,24}$ However, a theoretical study of $\mathrm{SiO}_{2}$ using the firstprinciples approach is difficult, if not intractable, in general, because of the complexity of the system and the intricate

a)Electronic mail: kieffer@umich.edu electronic structure of oxygen ions. ${ }^{32}$ Under these circumstances, the use of interatomic potentials would be preferable, provided that they are sufficiently accurate. In this approach, atomic interactions are described by analytically explicit two- or many-body potentials. These potentials are determined empirically, i.e., they are chosen so as to give the best fit to a set of experimental quantities. ${ }^{33}$ For silica, several empirical potentials have been discussed in the literature. ${ }^{34}$ Invariably, these interaction models assume static partial charges for $\mathrm{Si}$ and $\mathrm{O}$. Initial parametrization of the charges associated with each species was based on experimental observations, and later it was refined using $a b$ initio calculations. For example, Tsuneyuki et al. have derived a simple two-body potential (TTAM) for silica based on $a b$ initio calculations of small clusters, ${ }^{30}$ where the use of fractional charges seems to be one of the main ingredients for the success of the TTAM potential model. ${ }^{35}$ The optimal charges for $\mathrm{Si}$ and $\mathrm{O}$ were determined to be +2.4 and -1.2 , not unlike those found by Erikson and Hostetler. ${ }^{34}$ Dynamically stable structures were obtained for a variety of silica polymorphs and liquid $\mathrm{SiO}_{2}$ under ambient pressure using the pairwise additive TTAM potential. ${ }^{35-37}$ However, the predicted $\mathrm{Si}-\mathrm{O}-\mathrm{Si}$ angle is consistently too small for the structure of $\alpha$-quartz under pressure. ${ }^{38}$ Recently, this potential model was used in the lattice dynamics calculations of the vibrational frequencies of $\alpha$-quartz, $\alpha$-cristobalite, coesite, and stishovite. ${ }^{39}$ The comparison with experiments is reasonable but, in general, the calculated stretching frequencies are somewhat low and the bending frequencies are too high. 
It was explicitly shown by van Beest $e t a l .{ }^{31}$ that, as the range of the interatomic forces goes beyond the nearest neighbors, the need arises for complementing microscopic information with macroscopic information to optimize the interaction potentials. These authors obtained a new twobody potential (BKS) for silica by iteratively fitting to $a b$ initio potential energy surface of a $\mathrm{H}_{4} \mathrm{SiO}_{4}$ cluster and optimizing the effective charges on the $\mathrm{Si}$ and $\mathrm{O}$ atoms to the bulk properties of quartz. ${ }^{31}$ In this model, only two different short-range interactions, namely those describing the $\mathrm{Si}-\mathrm{O}$ bond and the $\mathrm{O}-\mathrm{O}$ nonbonded interactions are considered. These modify the Coulomb repulsion and ensure the tetrahedral arrangement of oxygen atoms around the silicon atom. The performance of this potential was critically evaluated through the calculation of the static and dynamical properties of several silica polymorphs with MD simulations. ${ }^{40}$ It was shown that, with the BKS potential, the calculated static structures and thermally induced $\alpha$ - to $\beta$-cristobalite transitions are reproduced within realistic pressure and temperature ranges. Although the $\mathrm{O}-\mathrm{Si}-\mathrm{O}$ angles are calculated correctly, the $\mathrm{Si}-\mathrm{O}-\mathrm{Si}$ angles are overestimated by about $6^{\circ}$, indicating a weaker $\mathrm{Si}-\mathrm{O}-\mathrm{Si}$ bending interaction. This can be easily understood because there is no intertetrahedral interaction in the BKS potential to account for the lone pair of electrons on oxygen responsible for the bending in the $\mathrm{Si}-$ $\mathrm{O}-\mathrm{Si}$ arrangement. The lack of the three-body interactions in BKS potential also makes it less satisfactory in calculating the vibrational properties. Although the high frequency $\mathrm{Si}-$ $\mathrm{O}-\mathrm{Si}$ asymmetric stretching modes have improved significantly over the TTAM potential, ${ }^{30}$ modes attributed to $\mathrm{O}-\mathrm{O}$ stretching are still systematically too low. In the worst case, the calculated frequency for this mode in $\alpha$-cristobalite is off by $340 \mathrm{~cm}^{-1}$. On the other hand, the calculated $\mathrm{O}-\mathrm{Si}-\mathrm{O}$ bending vibrations are always too high. ${ }^{40}$ In short, the BKS potential gives very good equilibrium structures for different polymorphs of silica and it also works very well in predicting the structural instabilities as a function of pressure and temperature. However, it appears that dynamical properties, such as phonon dispersion and infrared spectra, can only be accurately reproduced by taking three-body interactions directly into account.

Several empirical potentials for silica that include threebody interactions have been reported in the literature. ${ }^{41,42}$ Our potential differs from those mostly in the functional forms chosen to describe the covalent attractive interactions and orientational constraints, e.g., the angular restoring forces within $\mathrm{Si}-\mathrm{O}-\mathrm{Si}$ and $\mathrm{O}-\mathrm{Si}-\mathrm{O}$ groups are symmetric with respect to the equilibrium bond angles. Moreover, the balance between covalent and ionic character of the $\mathrm{Si}-\mathrm{O}$ bond is controlled by a charge transfer functional. According to Pauling's electronegativity rule, the $\mathrm{Si}-\mathrm{O}$ bond is about $50 \%$ ionic. Hence, fractional charge is deemed necessary to model the mixed covalent-ionic bonding characteristics of $\mathrm{SiO}_{2}$. In our model, the effective charges localized on $\mathrm{Si}$ and $\mathrm{O}$ atoms are dynamically determined based on the immediate atomic environment during the MD simulations. This feature can accommodate the drastic charge redistribution associated with the breaking and formation of the $\mathrm{Si}-\mathrm{O}$ bonds. But, even within an intact bond, subtle charge fluctuations result- ing from bond stretching vibrations can be accounted for with this functional. The refinement of this feature constitutes the principal improvement over the initial form of our interaction model. ${ }^{14}$ This enhancement was key to a better description of the high-temperature properties of silica. In the present paper we report our findings on the mechanism of the thermally induced structural transformation from $\alpha$ - to $\beta$-cristobalite, the structure and dynamics of the resulting $\beta$ cristobalite, and the origin of the negative thermal expansion in this phase.

\section{POTENTIAL MODEL AND COMPUTATIONAL DETAILS}

Because of the high degree of charge localization in silica, early models used to simulate structural properties of this system used formal ionic charges. Later on, to better account for the covalency of the $\mathrm{Si}-\mathrm{O}$ bond, fractional charges were used. All models with formal ionic charges $\left(\mathrm{Si}^{4+}\right.$ and $\left.\mathrm{O}^{2-}\right)$ generally give bulk moduli significantly larger than the experimental values; it takes fractional charges of nearly half the formal ones to best reproduce the observed structural and elastic behavior of crystalline silicates. ${ }^{34}$ Furthermore, it is often held that the single minimum two-body central potentials cannot properly describe systems where directional bonding is present. ${ }^{29,33,43}$ The charge transfer three-body potential model used here includes a Coulomb term, a Born-Huggins-Mayer repulsive term, ${ }^{44}$ and a three-body term. The potential energy for a given particle is

$$
\begin{aligned}
\phi_{i}= & q_{i} \sum_{j=1}^{N} \frac{q_{j}}{4 \pi \varepsilon_{0} r_{i j}}+\sum_{i=1}^{N C} C_{i j} e^{\left(\sigma_{i}+\sigma_{j}-r_{i j}\right) \cdot \rho_{i j}} \\
& +\sum_{j=1}^{N C-1} \sum_{k=j+1}^{N C}\left(\varphi_{i j}+\varphi_{i k}\right) e^{-\gamma_{i j k}\left(\bar{\theta}-\theta_{i j k}\right)^{2}},
\end{aligned}
$$

where $\varepsilon_{0}$ is the dielectric constant of vacuum, $r_{i j}$ is the interatomic distance, and $q_{i}$ is the charge. The charge of each atom is evaluated according to $q_{i}=q_{i}^{\varnothing}-\Sigma_{j=1}^{N C} \delta_{i j} \zeta_{i j}$, where $q_{i}^{\varnothing}$ is the charge of the isolated atom and $\zeta_{i j}$ $=\left(1+e^{b\left(r_{i j}-a\right)}\right)^{-1}$ is the charge transfer function, $a$ and $b$ are empirical parameters. Electroneutrality is assured by requiring that $\delta_{i j}=-\delta_{j i}$. The term $\left(\varphi_{i j}+\varphi_{i k}\right) e^{-\gamma_{i j k}\left(\bar{\theta}-\theta_{i j k}\right)^{2}}$, where $\varphi_{i j}=-C_{i j}\left(\kappa_{i j} / \eta_{i j}\right) \zeta_{i j} e^{\left(\lambda_{i j}-r_{i j}\right) \eta_{i j}}, C_{i j}=A_{i j}\left[\left(1+\left(z_{i} /\right.\right.\right.$ $\left.\left.n_{i}\right)+\left(z_{j} / n_{j}\right)\right]$, and $z_{i}$ is the valence, and $n_{i}$ is the number of electrons in the outer shell of atom $i$, models covalent bonding by acting in the radial and angular direction, as defined by triplets of particles. The long-range effect of Coulomb interactions has been evaluated using the Ewald summation method, both in real and reciprocal space. ${ }^{45,46}$ The components of the three-body terms acting radially between the centers of mass of the particles, $\varphi_{i j}$ $=-C_{i j}\left(\kappa_{i j} / \eta_{i j}\right) \zeta_{i j} e^{\left(\lambda_{i j}-r_{i j}\right) \eta_{i j}}$, are purely attractive. The magnitude of this attraction is modulated by the angular term, $e^{-\gamma_{i j k}\left(\bar{\theta}-\theta_{i j k}\right)^{2}}$ which is symmetric with respect to an equilibrium bond angle $\bar{\theta} . \theta_{i j k}$ is the angle formed by the bond vectors $r_{i j}$ and $r_{i k}$. In this potential model, both Coulombic and three-body terms are complementary, as con- 
TABLE I. Optimized potential parameters for cristobalite silica.

\begin{tabular}{|c|c|c|c|c|c|}
\hline \multicolumn{2}{|l|}{ Element } & $\sigma_{i}(\mathrm{~nm})$ & $n_{i}$ & $z_{i}$ & $q_{i}^{\varnothing}$ \\
\hline $\mathrm{Si}$ & \multicolumn{2}{|c|}{0.1010} & 8 & +4 & +4 \\
\hline $\mathrm{O}$ & \multicolumn{2}{|c|}{0.1430} & 8 & -2 & -2 \\
\hline Pair & $A_{i j}\left(10^{-19} \mathrm{~J}\right)$ & $\rho_{i j}\left(\mathrm{~nm}^{-1}\right)$ & $\lambda_{i j}(\mathrm{~nm})$ & $\eta_{i j}\left(\mathrm{~nm}^{-1}\right)$ & $\kappa_{i j}\left(\mathrm{~nm}^{-1}\right)$ \\
\hline $\mathrm{Si}-\mathrm{Si}$ & 0.1600 & 34.5 & 0.0 & 0.0 & 34.5 \\
\hline $\mathrm{Si}-\mathrm{O}$ & 0.1800 & 36.7 & 2.6 & 3.2 & 36.7 \\
\hline $\mathrm{O}-\mathrm{O}$ & 0.2500 & 19.5 & 0.0 & 0.0 & 19.5 \\
\hline \multicolumn{2}{|c|}{ Charge transfer } & $\delta_{i j}(\mathrm{e})$ & $a(\mathrm{~nm})$ & $b\left(\mathrm{~nm}^{-1}\right)$ & \\
\hline & & 0.2170 & 0.24 & 80 & \\
\hline \multicolumn{2}{|c|}{ Triplet } & $\gamma_{i j k}\left(\operatorname{rad}^{-2}\right)$ & $\theta(\mathrm{rad})$ & & \\
\hline \multicolumn{2}{|c|}{$\mathrm{O}-\mathrm{Si}-\mathrm{O}$} & 0.2 & 1.91 & & \\
\hline \multicolumn{2}{|c|}{$\mathrm{Si}-\mathrm{O}-\mathrm{Si}$} & 0.3 & 2.48 & & \\
\hline
\end{tabular}

trolled by the charge transfer function. The values for the various parameters are summarized in Table I.

The system in present MD simulations has 648 particles (216 Si and $432 \mathrm{O}$ ), using as initial configurations the ideal coordinates of $\alpha$-cristobalite according to the International Tables for Crystallography. ${ }^{47} \alpha$-cristobalite can be simulated in a cubic simulation box, because, despite having a tetragonal unit cell $\left(a_{0}=4.97 \AA, c_{0}=6.92 \AA\right)$, the structure is also pseudocubic if the cell parameters are chosen such that $a_{0}^{\prime}$ $=c_{0}^{\prime}=\sqrt{2} a_{0}=7.02 \AA$. In this setup, there are 24 atoms per unit cell, and there is a $1.44 \%$ expansive distortion in the $c$ direction. Periodic boundary conditions are always assumed in simulations involving bulk specimens. The time step chosen for the simulations is 2 fs. Initially a Gaussian velocity distribution is assigned to the atoms in such a way that the system retains a temperature of about $300 \mathrm{~K}$. The simulated $\alpha$-cristobalite structure after 20 ps constant pressureconstant temperature equilibration at $0 \mathrm{~Pa}$ and $300 \mathrm{~K}$ is displayed in Fig. 1. During this period the structure is allowed to relax and the simulation box contracts by $1.95 \%$ in the $c$ direction. Sixfold (six $\mathrm{Si}$ and six $\mathrm{O}$ atoms) rings can be easily seen in both the ball \& stick and polyhedral model. The density of this system at room temperature is $2.35 \mathrm{~g} / \mathrm{cm}^{3}$, which agrees perfectly with the experimental density of $\alpha$-cristobalite. ${ }^{48}$

The thermally induced phase transformation between $\alpha$ and $\beta$-cristobalite is studied by heating up the system at different heating rates. Temperature ramping is achieved by velocity scaling and the density adjusts according to the Anderson constant-pressure algorithm ${ }^{49}$ or Parrinello-Rahman constant-pressure algorithm. ${ }^{50}$ With the former algorithm the volume is only allowed to change isotropically, whereas with the latter the simulation box is also allowed to undergo shear deformations. The extended system Nosé-Hoover constant temperature algorithm, ${ }^{51}$ together with the general form of the Parrinello-Rahman constant pressure algorithm, are employed in the NPT ensembles. NVT and NVE ensembles are also used according to the properties to be investigated. The static properties as well as the short-range order of $\alpha$ - and $\beta$-cristobalite are investigated at different temperatures. The dynamic properties of the system are analyzed through the calculations of the vibrational density of states and the infrared spectra. The vibrational density of states reported here is

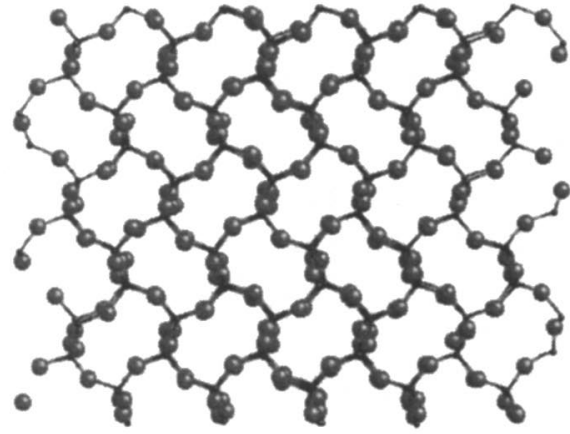

(a)

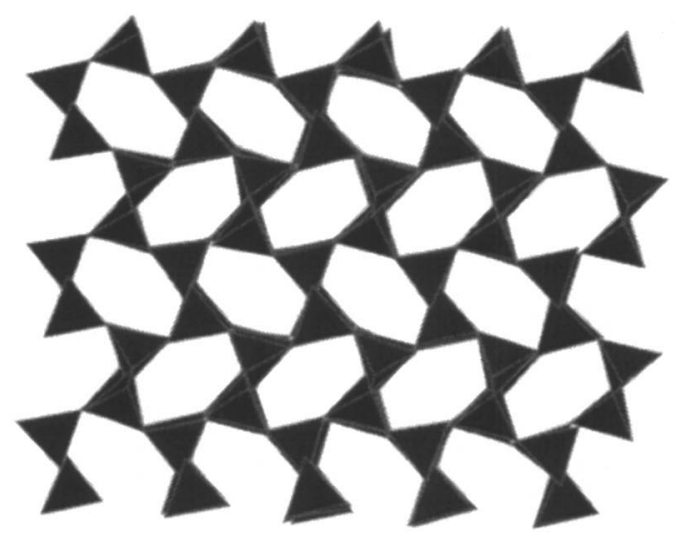

(b)

FIG. 1. (a) Atomic positions in $\alpha$-cristobalite (large spheres are $\mathrm{O}$ atoms and the small spheres are $\mathrm{Si}$ atoms); (b) $\alpha$-cristobalite structure at $300 \mathrm{~K}$ represented by $\mathrm{SiO}_{-}$tetrahedra; both views are along the $\langle 110\rangle$ direction. 


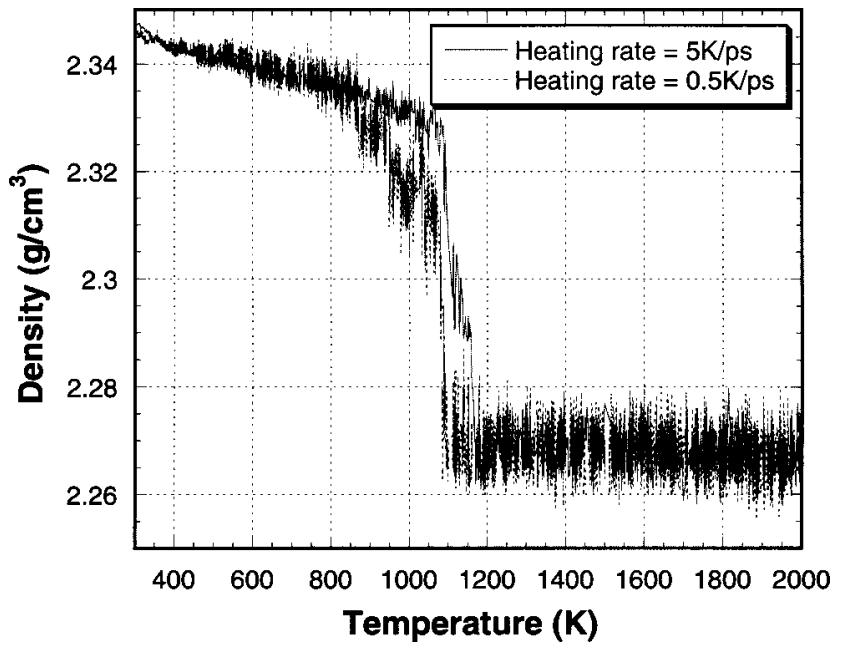

FIG. 2. Heating rate dependence of the thermally induced $\alpha$ - to $\beta$-cristobalite transformation. (Slower rate results in lower onset transformation temperature.)

based on the Fourier transform of the velocity autocorrelation function. ${ }^{52,53}$ The infrared spectra are computed from the Fourier transform of the instantaneous total cell dipole moment autocorrelation function..$^{54,55}$

\section{RESULTS AND DISCUSSIONS}

The easiest way to detect the thermally induced $\alpha$ - to $\beta$-cristobalite transformation is by looking at the density versus temperature curves as shown in Fig. 2. With $5 \mathrm{~K} / \mathrm{ps}$ heating rate, the transformation begins at $1100 \mathrm{~K}$ and finishes at 1200 K. As it can be seen in Fig. 2, the transformation temperature is heating rate dependent. With a ten times slower heating rate the transformation initiates at $850 \mathrm{~K}$ and finishes at $1100 \mathrm{~K}$. Based on this comparison, it is clear that the high heating rates in our simulations are in part responsible for overshooting the experimentally determined transformation temperature of $540 \mathrm{~K}$. Moreover, we believe that the absence of defects and grain boundaries in our simulated structures suppresses the transformation upon heating (and cooling for that matter). Similar transformation behaviors are observed whether Anderson or Parrinello-Rahman constant pressure algorithms were used. In other words, the structure does not undergo significant shear deformation upon transformation. As is apparent for both heating rates, there are several steps on the density curves before $\alpha$-cristobalite completely transforms into $\beta$-cristobalite. A series of snapshots in Fig. 3 reveals how the formation of the new phase begins as an extended structural defect (near the top of the picture). The defect then sweeps through the structure, and in its wake $\beta$-cristobalite prevails after the local phase character has oscillated several times between $\alpha$ - and $\beta$-cristobalite. (Note that seen in the $\langle 110\rangle$ direction, as shown here, rings in the $\alpha$-cristobalite structure project as rectangular entities, slightly tapered towards the middle and stacked in alternating orientations rotated by $90^{\circ}$. Rings in $\beta$-cristobalite, on the other hand project approximately as hexagons and appear more circular and isotropic.) Accordingly, $\alpha$-cristobalite gradually transforms into $\beta$-cristobalite in the thermally in-

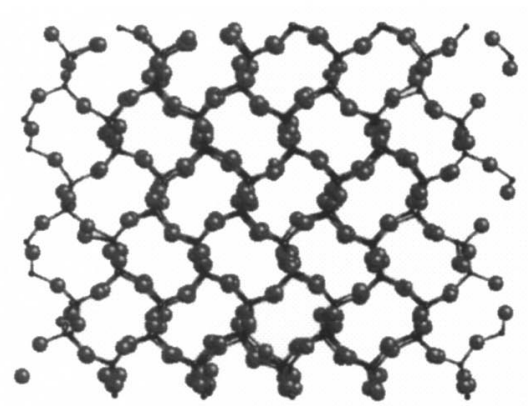

(a)

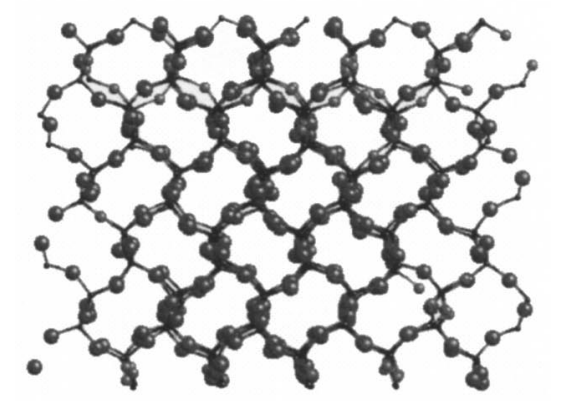

(b)

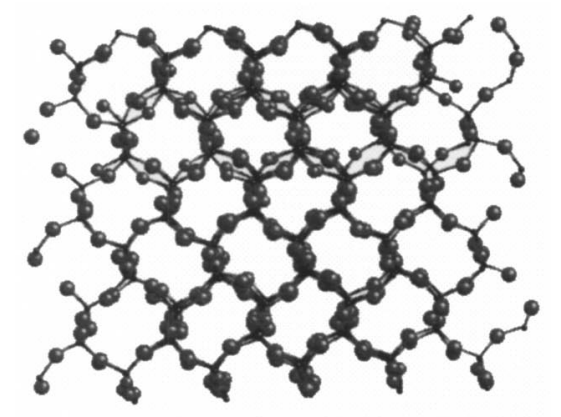

(c)

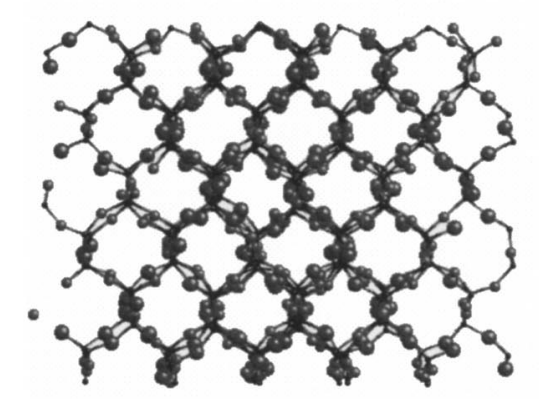

(d)

FIG. 3. New phase forming and sweeping through the simulation box during the thermally induced $\alpha$ - to $\beta$-cristobalite transformation.

duced transformation. In comparison, as we reported earlier, ${ }^{14}$ the transformation occurs abruptly when induced by a pressure change at room temperature. Moreover, as also detailed in this earlier paper, the transformation between $\alpha$ and $\beta$-cristobalite is fourfold degenerate, following the $X_{4}$ irreducible representation, but only two different enantiomor- 


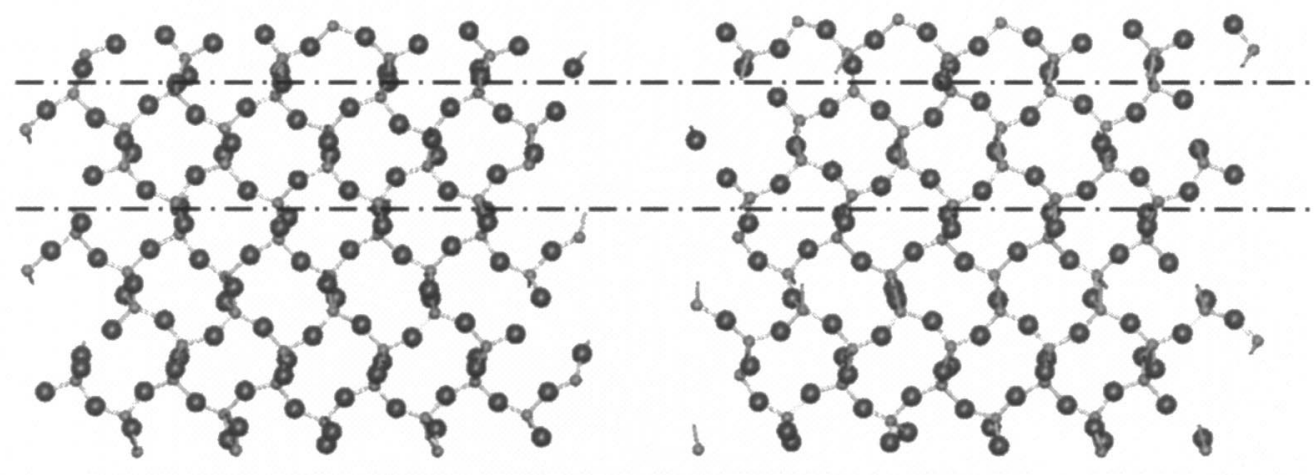

(a)

(b)

FIG. 4. Two adjacent slices of the structure in Fig. 3(c) showing two ways of transformation into $\beta$-cristobalite according to the $\mathrm{X}_{4}$ irreducible representation.

phic states result because of symmetry. In the lowtemperature pressure-induced transformation, the entire structure always converted uniformly into one of these enantiomorphic states, invoking two of the four transformation paths that did not break symmetry. By contrast, the thermally induced transformation can result in both states simultaneously. This gives rise to the disorder observed in Fig. 3. The irregularity that is apparent in the second row of rings from the top in Fig. 3(c) is actually the superposition of an alternation between rings of different enantiomorphic orientations. To illustrate this, we show in Fig. 4 two adjacent slices cut from the simulated crystal perpendicular to the $\langle 110\rangle$ direction. Each slice contains only one layer of rings. The second row reveals rings that are halfway in between $\alpha$ and $\beta$-cristobalite, and have different orientations from one layer to the next. However, within each row, rings are quite regular. In fact, when viewed from the $\langle 1 \overline{1} 0\rangle$ direction, the defect is not visible-the entire structure appears like $\alpha$-cristobalite.

As for the pressure-induced transformation, there is relatively little change in the short-range order between the $\alpha$ and $\beta$-cristobalite structures when the transformation is thermally induced. Figure 5 displays the radial distribution functions $g(r)_{\mathrm{O}-\mathrm{O}}, g(r)_{\mathrm{Si}-\mathrm{O}}, g(r)_{\mathrm{Si}-\mathrm{Si}}$ from 400 to $1600 \mathrm{~K}$, at $200 \mathrm{~K}$ intervals. There is no shift of the first peak in the $\mathrm{Si}-\mathrm{Si} \mathrm{RDF}$ to shorter length with temperatures in this temperature range, which is quite different from recently reported MD simulations of cristobalite. ${ }^{19,56}$ As shown in Fig. 5 , the most significant changes in the individual pair distribution functions between $\alpha$ - and $\beta$-cristobalite occur in $g(r)_{\mathrm{O}-\mathrm{O}}$. There are slight changes in $g(r)_{\mathrm{Si}-\mathrm{Si}}$, and in $g(r)_{\mathrm{Si}-\mathrm{O}}$. It can easily be understood that the transformation between $\alpha$ - and $\beta$-cristobalite most strongly affects the positions of oxygen atoms relative to one another, because the displacive phase transition is primarily associated with changes in the orientations of the $\mathrm{SiO}_{4}$ tetrahedra, and only small symmetry breaking displacements of the $\mathrm{Si}$ cations. These pair correlation functions also demonstrate that $\alpha$-cristobalite is more ordered on nearly all length scales beyond the level of the tetrahedra, as indicated by the larger number of distinct peaks and smaller peak widths. In both phases $g(r)_{\mathrm{Si}-\mathrm{Si}}$ exhibits much stronger correlations at higher $r$ than either $g(r)_{\mathrm{O}-\mathrm{O}}$ or $g(r)_{\mathrm{Si}-\mathrm{O}}$. This reveals that during the phase transformation the positions of $\mathrm{Si}$, i.e., the centers of gravity of the tetrahedra, are less affected than the orientations of these tetrahedra, which define the $\mathrm{O}$ positions.

The $\mathrm{Si}-\mathrm{Si}, \mathrm{Si}-\mathrm{O}, \mathrm{O}-\mathrm{O}$ distances and $\mathrm{O}-\mathrm{Si}-\mathrm{O}$ and $\mathrm{Si}-$ $\mathrm{O}-\mathrm{Si}$ angles are calculated from the equilibrium structures at each temperature (100 K interval from 400 to $2000 \mathrm{~K}$ ). Figure 6 shows the temperature dependence of the ensemble average of these values. Figure 6(a) confirms that, with increasing temperature, the $\mathrm{Si}-\mathrm{O}$ bonds continuously expand through the transformation; ${ }^{13}$ the transition temperature cannot be reliably discerned from this data. The $\mathrm{O}-\mathrm{O}$ and $\mathrm{Si}-\mathrm{Si}$ distances exhibit similar behavior [see Figs. 6(b) and 6(c)]. In Fig. 6(b), the $\mathrm{O}-\mathrm{Si}-\mathrm{O}$ angle is almost invariant during the thermally induced phase transformation. The most obvious change during the phase transformation is associated with the intertetrahedral $\mathrm{Si}-\mathrm{O}-\mathrm{Si}$ angle as seen in Fig. 6(c). There is a $0.5 \mathrm{deg}$ increase during the phase transformation, but it is much smaller than the $4^{\circ}$ increase determined by NMR experiments. ${ }^{9}$ Our present MD simulations indicate that the bond lengths, as well as the average bond angles, are almost invariant during the thermally induced phase transition. The rigidity of $\mathrm{SiO}_{4}$ tetrahedra in silica in our simulations is consistent with the analysis of experimental results by Hatch and Ghose. ${ }^{4}$ The rigidity of the tetrahedra during the phase transition observed in our simulations also supports the recent RUM model of Dove et al. ${ }^{57}$ Since the topology of both $\alpha$ and $\beta$-cristobalite is the same, the phase transition must occur by cooperative spatial rearrangements of the tetrahedra, during which the bond lengths and bond angles are conserved.

Our previous MD simulations of the pressure-induced phase transformation in cristobalite ${ }^{14}$ already revealed that all displacements necessary for the symmetry change in cristobalite could be realized by rotation of $\mathrm{Si}-\mathrm{O}-\mathrm{Si}$ planes. The orientation of the $\mathrm{Si}-\mathrm{O}-\mathrm{Si}$ bridges can be tracked by the normal $n_{i}$, to the plane that contains all three atoms, which is defined as

$$
\boldsymbol{n}_{i}=\frac{\boldsymbol{R}_{1} \times \boldsymbol{R}_{2}}{\left|\boldsymbol{R}_{1} \times \boldsymbol{R}_{2}\right|},
$$



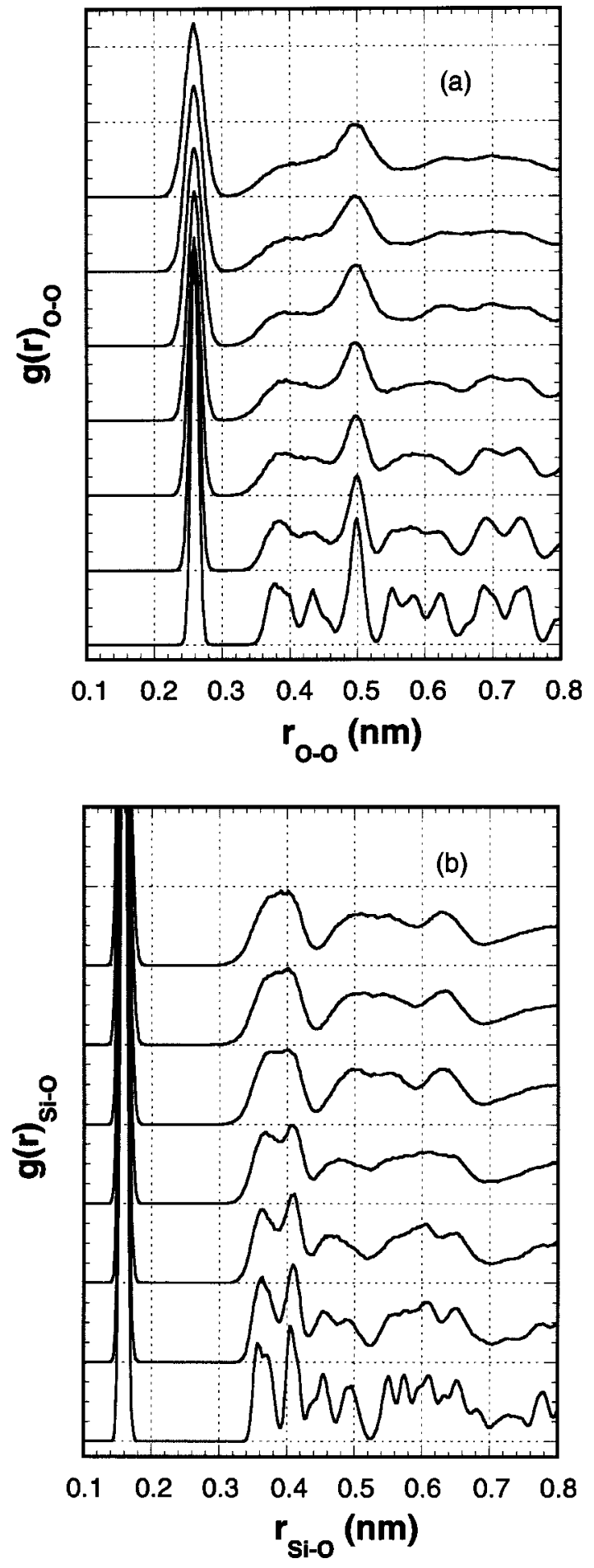

where $\boldsymbol{R}_{1}$ and $\boldsymbol{R}_{2}$ are the $\mathrm{Si}-\mathrm{O}$ vectors in the $\mathrm{Si}-\mathrm{O}-\mathrm{Si}$ plane. During the pressure-induced transformation at room temperature, all $\mathrm{Si}-\mathrm{O}-\mathrm{Si}$ plane normal vectors cooperatively rotate by $90^{\circ} .{ }^{14}$ The time correlation of individual $\mathrm{Si}-\mathrm{O}-\mathrm{Si}$ plane normal is defined as

$$
C_{n_{i}}(t)=\boldsymbol{n}_{i}(t) \cdot \boldsymbol{n}_{i}(0) \text {. }
$$

The Si-O-Si plane normal in $\alpha$-cristobalite at $300 \mathrm{~K}$ is chosen as the reference plane normal $\boldsymbol{n}_{i}(0)$. The motion of an individual normal vector relative to its initial orientation is described by the plane normal correlation function $C_{n_{i}}(t)$. If

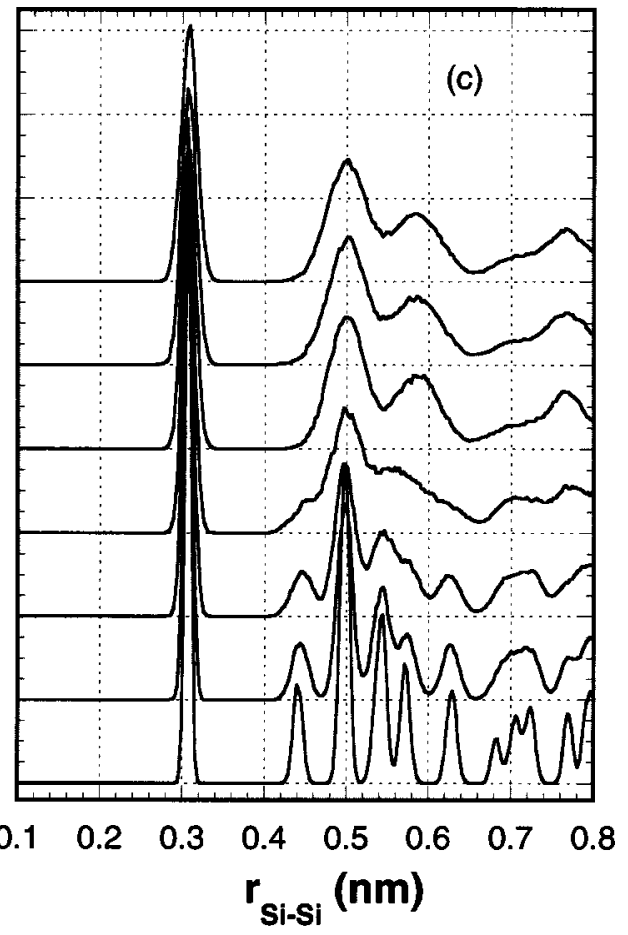

FIG. 5. Radial distribution functions (a) $g(r)_{\mathrm{O}-\mathrm{O}}$; (b) $g(r)_{\mathrm{Si}-\mathrm{O}} ;$ (c) $g(r)_{\mathrm{Si}-\mathrm{Si}}$ from 400 to $1600 \mathrm{~K}$ at $200 \mathrm{~K}$ intervals; the curves are offset vertically for clarity. the value of $C_{n_{i}}(t)=1$, the normal vector $\boldsymbol{n}_{i}(t)$ is at the same orientation as reference plane normal; if it is 0 then the plane has rotated by $90^{\circ}$ and local phase character is that of $\beta$-cristobalite. The value of the plane normal correlation function therefore serves as an indicator for the local order of the structure. By tracking the plane normal correlation function, we can determine the various states visited by the simulated configuration in the course of the transformation. Figure 7 shows a series of histograms reflecting the probability density $P\left(C_{n_{i}}(t)\right)$ for the plane normal correlation function 

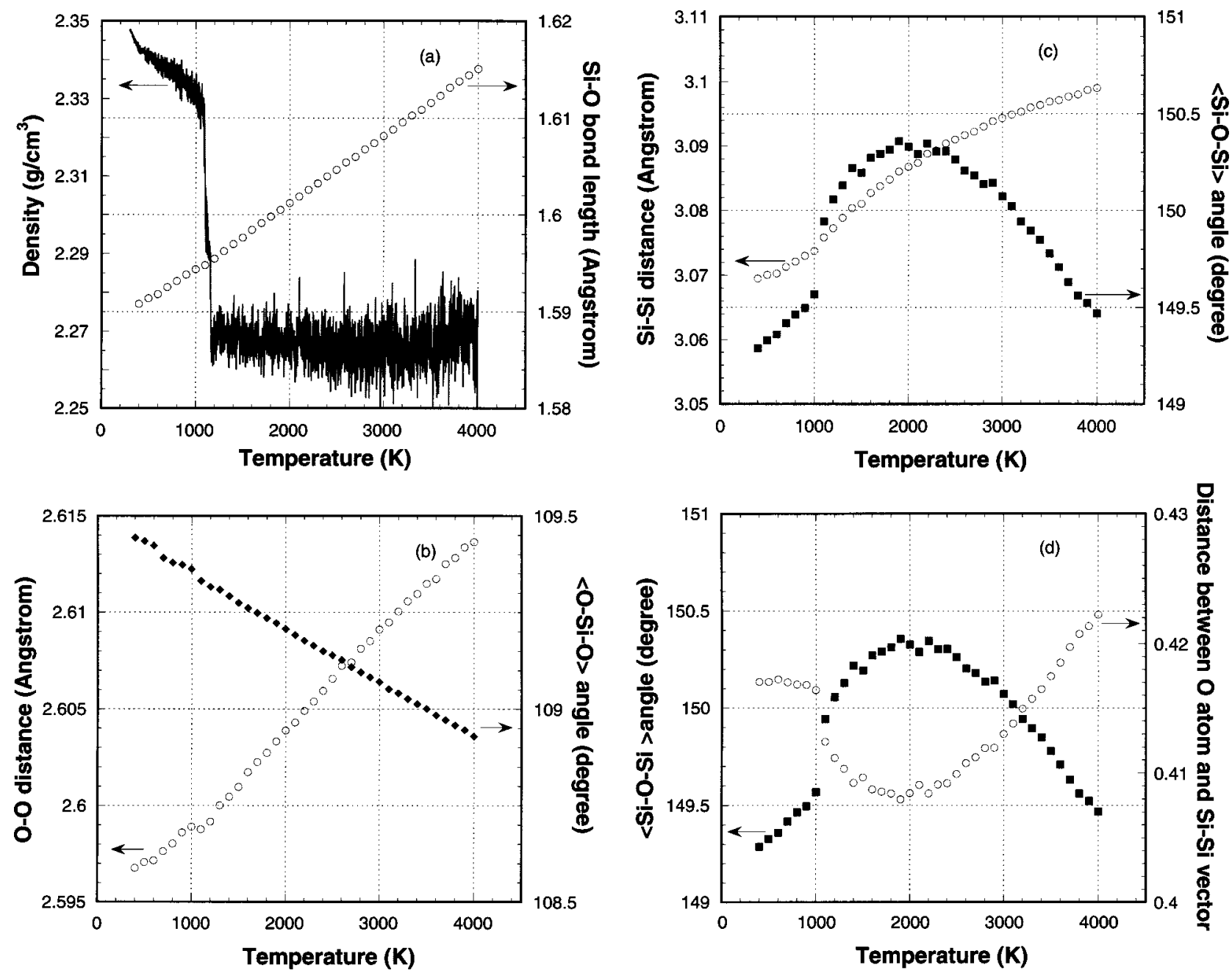

FIG. 6. Bond length and bond angle evolution with temperature. (a) $\mathrm{Si}-\mathrm{O}$ bond length compared to density; (b) O-O and $\mathrm{O}-\mathrm{Si}-\mathrm{O}$ angle; (c) $\mathrm{Si}-\mathrm{Si}$ distance and $\mathrm{Si}-\mathrm{O}-\mathrm{Si}$ angle; (d) $\mathrm{Si}-\mathrm{O}-\mathrm{Si}$ angle and the distance between an $\mathrm{O}$ atom and the vector connecting the two $\mathrm{Si}$ atoms it is bonded to.

of an individual $\mathrm{Si}-\mathrm{O}-\mathrm{Si}$ bridge, sampled over time. The magnitude of this distribution translates directly into time spent in a certain orientation. According to Fig. 7(a), at 400 $\mathrm{K}, C_{n_{i}}(t)$ always stays very close to 1 , which means that the $\mathrm{Si}-\mathrm{O}-\mathrm{Si}$ plane spends most of the time around the reference $\alpha$-cristobalite state. We refer to this as an $\alpha_{1}$-state to allow for the enantiomorphic $\alpha_{2}$ state that can be reached during the transition. Upon reaching the transformation temperature at a $5 \mathrm{~K} / \mathrm{ps}$ heating rate as seen in Fig. 7(b), the structure eventually overcomes the energy barrier between $\alpha$ - and $\beta$-cristobalite states. The $\mathrm{Si}-\mathrm{O}-\mathrm{Si}$ plane begins to rotate from the $\alpha_{1}$ - to the $\beta$-orientation [ $C_{n_{i}}(t)=0$ ], but because of thermal fluctuations the $\mathrm{Si}-\mathrm{O}-\mathrm{Si}$ plane orientation overshoots towards $\alpha_{2}$ state $\left[C_{n_{i}}(t)=-1\right]$. However, it returns very quickly and at this low temperature still spends about $90 \%$ of the time close to the $\alpha_{1}$ state. Upon further increasing the temperature past the transformation point the $C_{n_{i}}(t)$ distribution evens out, which is to say that the $\mathrm{Si}-\mathrm{O}-\mathrm{Si}$ plane now persistently oscillates between $\alpha_{1}$ and $\alpha_{2}$ orientations [Fig. 7(c)]. There are still distinct maxima at +1 and -1 , but there is also an almost equal probability of finding plane orientations in the vicinity of $C_{n_{i}}(t)=0$, i.e., consistent with the actual $\beta$-cristobalite. While individual $\mathrm{Si}-\mathrm{O}-\mathrm{Si}$ planes oscillate between $\alpha_{1}$ and $\alpha_{2}$ configurations, the average plane orientation in $\beta$-cristobalite at any given moment forms a $90^{\circ}$ angle with that of $\alpha$-cristobalite as shown in Fig. 7(e). Based on this observation, high cristobalite appears to be the result of time averaging thermally driven oscillations between two enantiomorphic $\alpha$ states. It is, however, important to note that a static $\beta$-cristobalite structure can be stable under the right circumstances, i.e., the configuration with $\mathrm{Si}-\mathrm{O}-\mathrm{Si}$ planes rotated by $90^{\circ}$ with respect to $\alpha$ states corresponds to an energy minimum. This is obvious from the pressure-induced $\alpha$ - to $\beta$-cristobalite phase transformation. At $300 \mathrm{~K}$ and $-2 \mathrm{GPa}$ tensile stress, $\alpha$-cristobalite transforms into $\beta$-cristobalite for which $\mathrm{Si}-\mathrm{O}-\mathrm{Si}$ plane orientations remain centered around $C_{n_{i}}(t)=0$ [Fig. 7(d)]. An illustration of the structural fluctuations in $\beta$-cristobalite is given in Fig. 8. To this end, the instantaneous ring structures of one single layer are recorded at $1200 \mathrm{~K}$, which corresponds to the temperature in Fig. 7(c). The ring structure varies with time and can look like $\alpha_{1}, \beta$ and $\alpha_{2}$ at different times. On a time average, however, the high symmetry of $\beta$-cristobalite is satisfied. The $\alpha$-like rings last much less that $1 \mathrm{ps}$ and vary from layer to layer, which means $\beta$-cristobalite is a true dynami- 

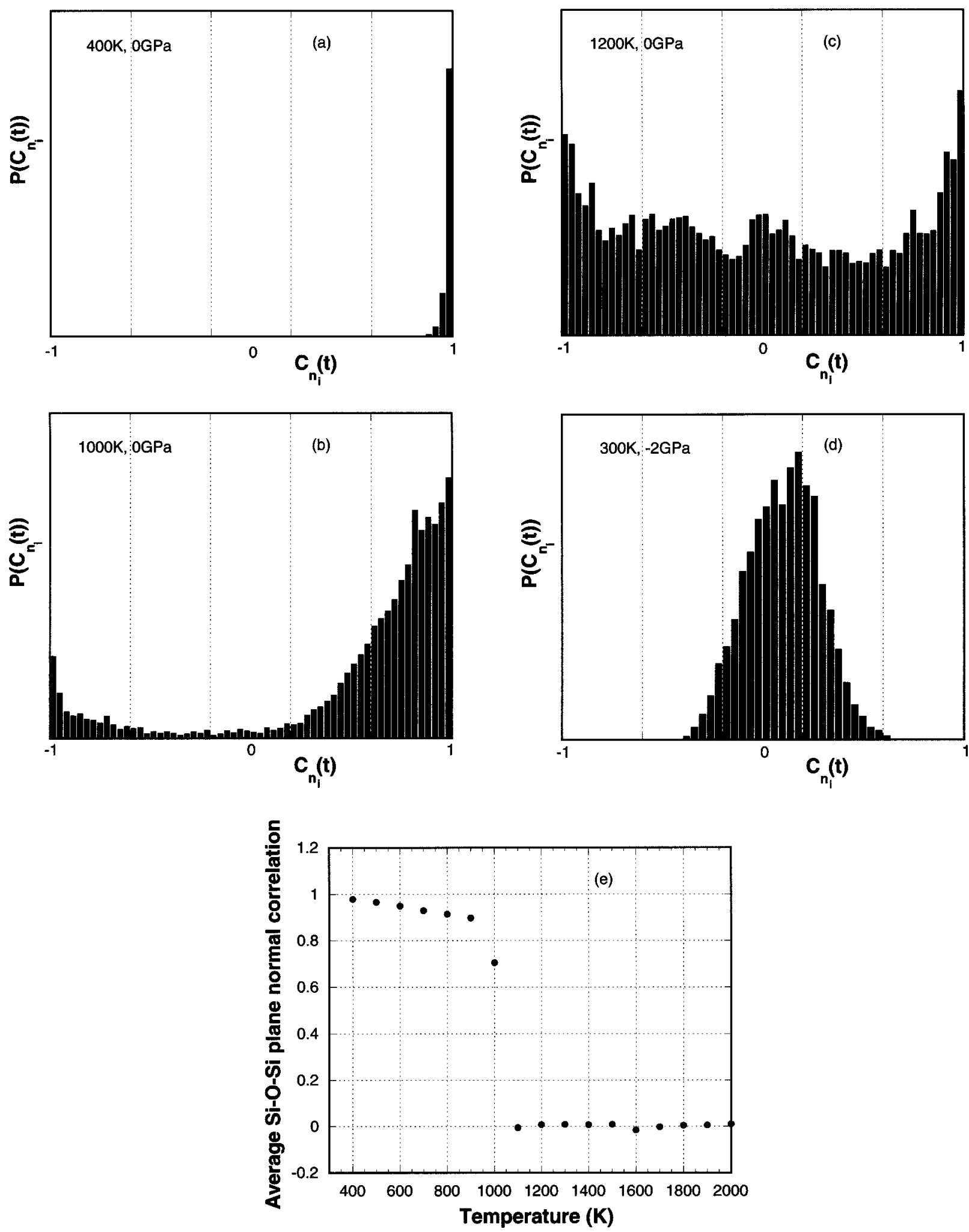

FIG. 7. Distributions of Si-O-Si plane normal correlations. (a) through (c): $P\left(C_{n_{i}}(t)\right)$ for an individual plane at different temperatures showing the effect of the thermally induced transformation; (d) $P\left(C_{n_{i}}(t)\right)$ for an individual plane after the pressure-induced transformation; (e) Evolution of the average Si-O-Si plane normal correlation with temperature.

cally disordered phase, as tacitly assumed in the RUM model, and not static or slowly evolving domains of $\alpha$-phase as proposed by other authors. ${ }^{4,22}$

The nature of the disorder in the $\beta$-cristobalite revealed by our simulations can be further ascertained by calculating quantities that can be directly compared with experiments, such as the nearest-neighbor $\mathrm{Si}-\mathrm{Si}-\mathrm{Si}$ angle distributions and the infrared spectra in both phases. Figure 9(a) shows the 


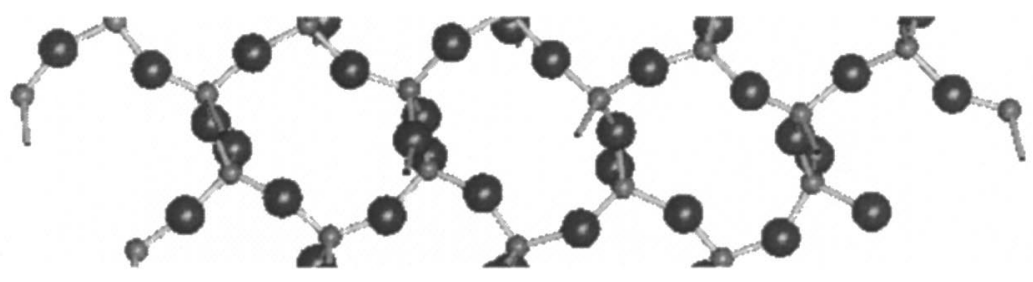

(a) $\alpha_{1}$-like rings

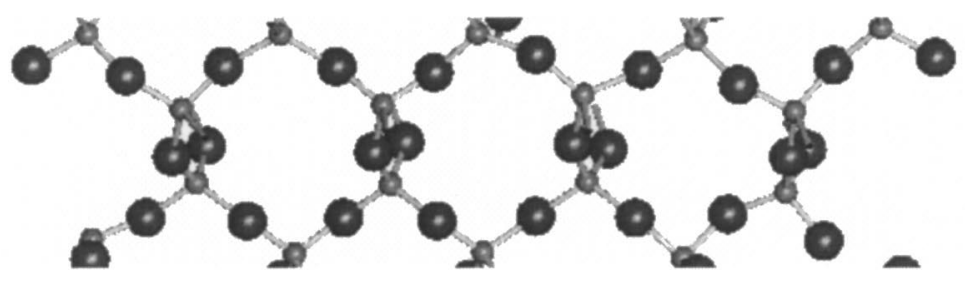

FIG. 8. Instantaneous ring structures in $\beta$-cristobalite at $1200 \mathrm{~K}$, revealing the oscillations between $\alpha_{1}$ and $\alpha_{2}$ states that constitute the dynamic disorder in $\beta$-cristobalite.

(b) $\beta$-like rings

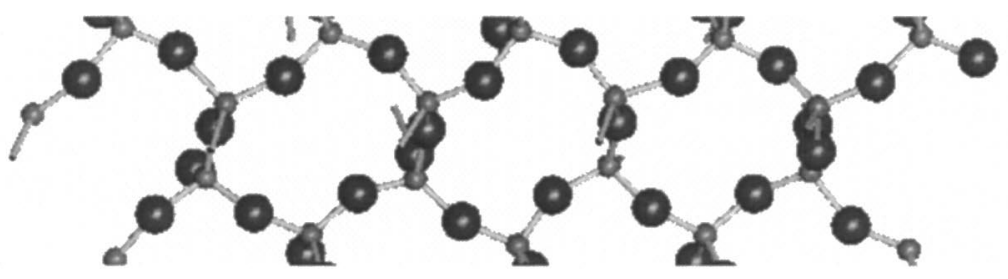

(c) $\alpha_{2}$-like rings

distributions of nearest-neighbor $\mathrm{Si}-\mathrm{Si}-\mathrm{Si}$ angle at different temperatures, averaged over 10000 time steps, after the system is equilibrated in the NPT ensemble. Accordingly, in the low-temperature phase, there are always two small peaks flanking the main peak around $110^{\circ}$. Upon transformation into the high-temperature phase, these two small peaks disappear and merge with the main peak. A single peak in this distribution is characteristic of $\beta$-cristobalite that results from the pressure-induced transformation at room temperature [Fig. 9(b)]. If any static domains of the low-temperature phase were to persist above the transition temperature, a trace of the sidelobes in the $\mathrm{Si}-\mathrm{Si}-\mathrm{Si}$ distribution would remain as well, since it reflects the near-range structural characteristics of the high-temperature phase. Experimentally, the $\mathrm{Si}-\mathrm{Si}-\mathrm{Si}$ angle can be extracted from neutron scattering data. This has been done for quartz, showing exactly the behavior described above. ${ }^{58}$ Although a strict comparison between experiment and simulation cannot be made for this particular measure, similarities in the phase behavior of quartz and cristobalite are, however, significant enough to lend indirect support to the assertions concerning the nature of $\beta$-cristobalite presented here.

Figure 10 shows the temperature dependence of the midinfrared spectra in both experiments ${ }^{59}$ and simulations. There are three major bands in the IR spectrum for cristobalite. The band at about $1100 \mathrm{~cm}^{-1}$ can be assigned to $\mathrm{Si}-\mathrm{O}-\mathrm{Si}$ asymmetric stretching vibrations, the narrow band at $800 \mathrm{~cm}^{-1}$ to $\mathrm{O}-\mathrm{Si}-\mathrm{O}$ bending motions, and the band around $500 \mathrm{~cm}^{-1}$ to $\mathrm{Si}-\mathrm{O}-\mathrm{Si}$ bending motions. ${ }^{55}$ Our simulated spectra are in good agreement with the experimental ones, both in terms of spectra peak positions and their relative intensities. Only the lowest-frequency peak appears at somewhat higher frequencies as compared to the experiments. Note that the $\mathrm{Si}-\mathrm{O}-\mathrm{Si}$ bending band has two peaks in $\alpha$-cristobalite. Upon transformation into $\beta$-cristobalite, the smaller of the two peaks (at $680 \mathrm{~cm}^{-1}$ ) disappears. ${ }^{10,59}$ This behavior, which can be attributed to the achievement of higher symmetry in the structure, is fully reproduced in our simulations. Again, since IR spectroscopy only probes the local environment (with correlation length of at most a few unit cells ${ }^{60}$ ), this represents further strong evidence against the "domain" model of the high-temperature phase. ${ }^{4,22}$ The $680 \mathrm{~cm}^{-1}$ peak would not completely disappear if static $\alpha$-domains existed above the transition temperature.

A number of experimental findings have been interpreted in terms of RUMs, typically in conjunction with the observation of low-frequency phonon vibrations with specific propagation directions. ${ }^{61}$ Moreover, a soft optic phonon nor- 

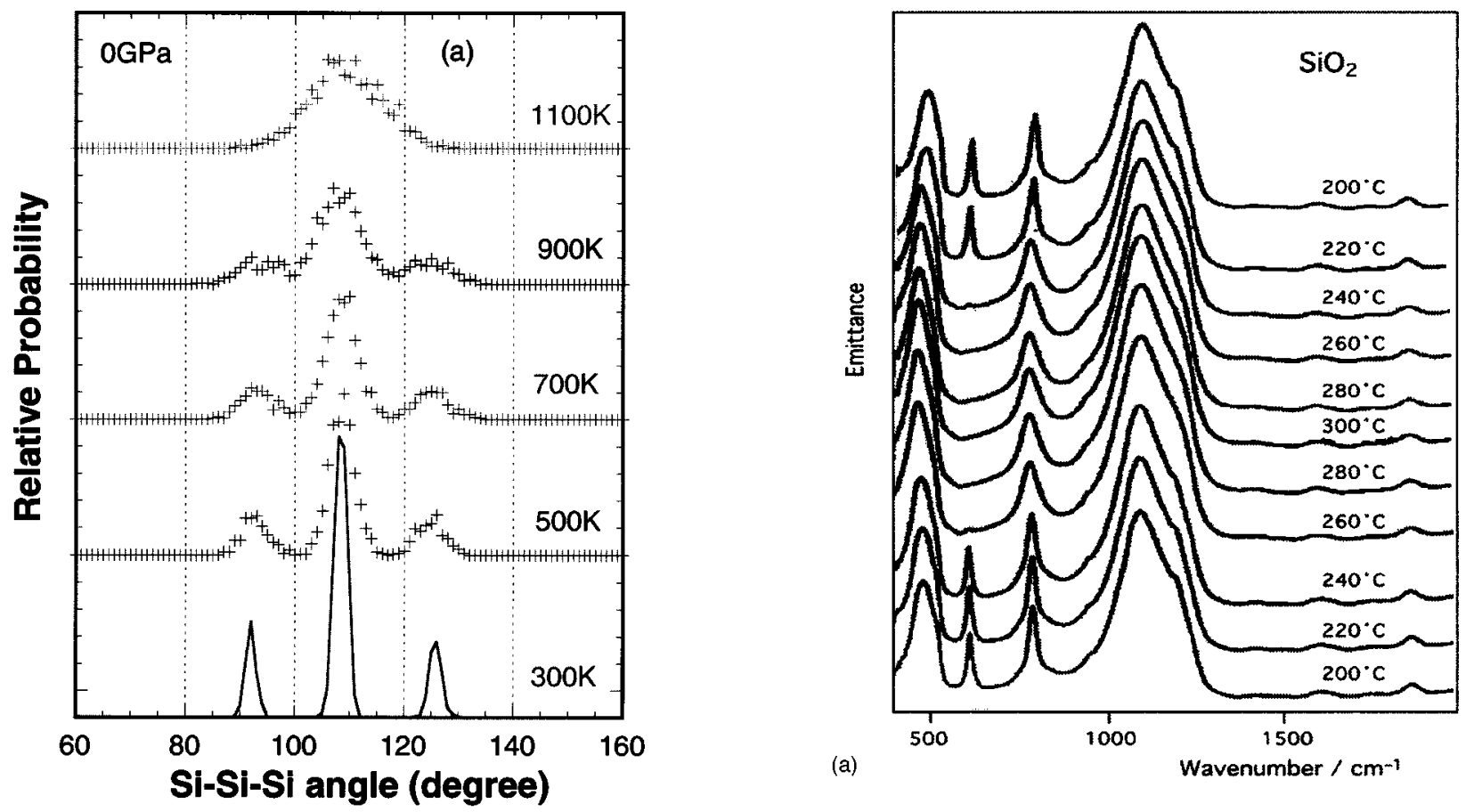

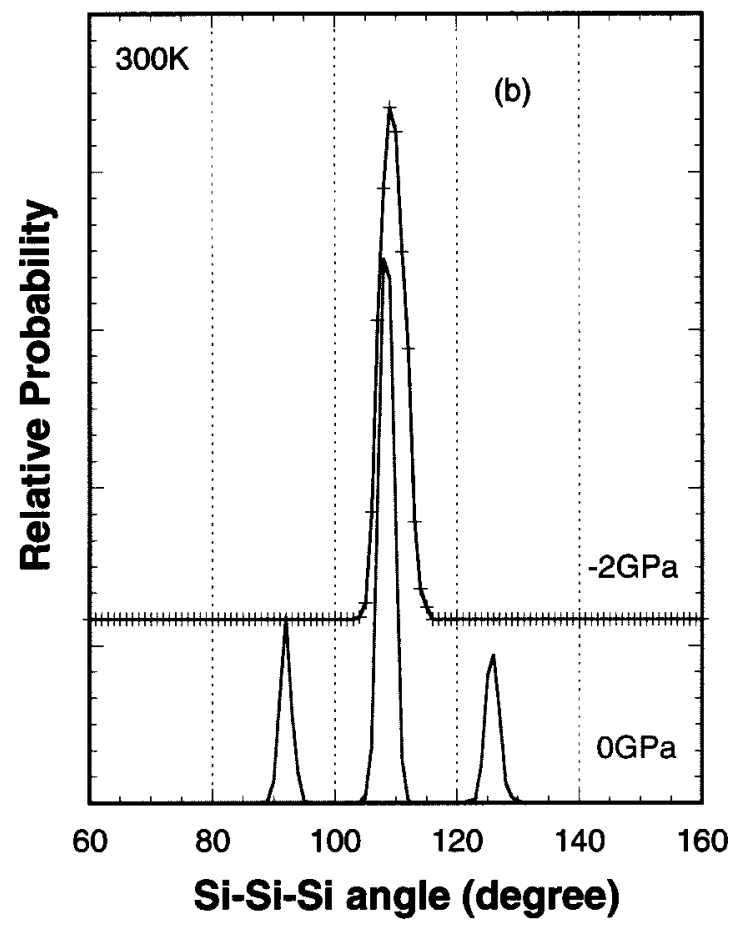

FIG. 9. Nearest-neighbor $\mathrm{Si}-\mathrm{Si}-\mathrm{Si}$ angle distribution. (a) Thermally induced $\alpha$-to- $\beta$ transformation; (b) Pressure-induced $\alpha$-to- $\beta$ transformation.

mal mode has been evidenced by inelastic neutron scattering $^{62}$ for the phase transition between $\alpha$ - and $\beta$-quartz. In our simulated cristobalite RUMs are apparent in the phonon density of states below $50 \mathrm{~cm}^{-1}$ [Fig. 11(a)]. In this very low-frequency regime, which is magnified in the inset, the density of states for $\alpha$-cristobalite varies roughly as $\nu^{2}$, as expected for the normal contribution from the acoustic modes. On the other hand, the density of states for $\beta$-cristobalite shows significant enhancement of the number of modes in the very low-frequency regime, which is consis- (a)

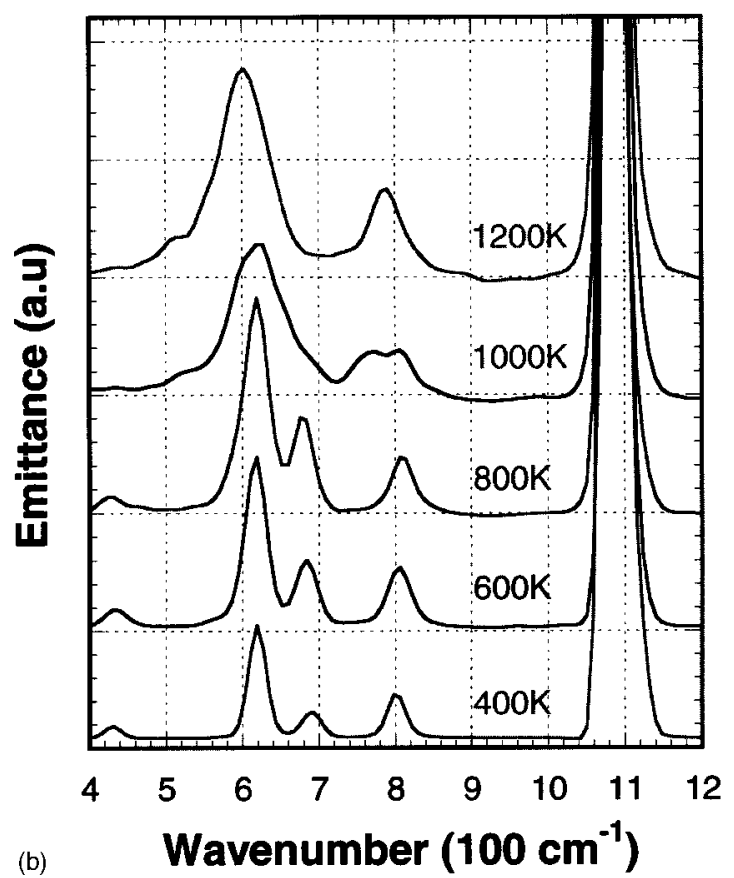

FIG. 10. Comparison between (a) experimentally measured and (b) MD simulated midinfrared spectra of cristobalite silica. Note the vanishing of the $680 \mathrm{~cm}^{-1}$ band as a result of the $\alpha$-to- $\beta$ transformation.

tent with the observation of characteristic diffuse scattering in the powder diffraction patterns of $\beta$-cristobalite ${ }^{6}$ and MD simulations. ${ }^{10}$ Furthermore, the low-frequency intensity in the density of states for $\beta$-cristobalite increases with increasing temperature, while in $\alpha$-cristobalite, the density of states remains quite invariant up to the transition temperature.

As demonstrated in experiments by Aumento (1966), ${ }^{63}$ Wright and Leadbetter (1975), ${ }^{22}$ Swainson and Dove (1995), ${ }^{11}$ the lattice parameter of $\beta$-cristobalite reaches a plateau or even decreases between 1000 and $1500{ }^{\circ} \mathrm{C}$. In recent $\mathrm{x}$-ray diffraction experiments using synchrotron radiation, 

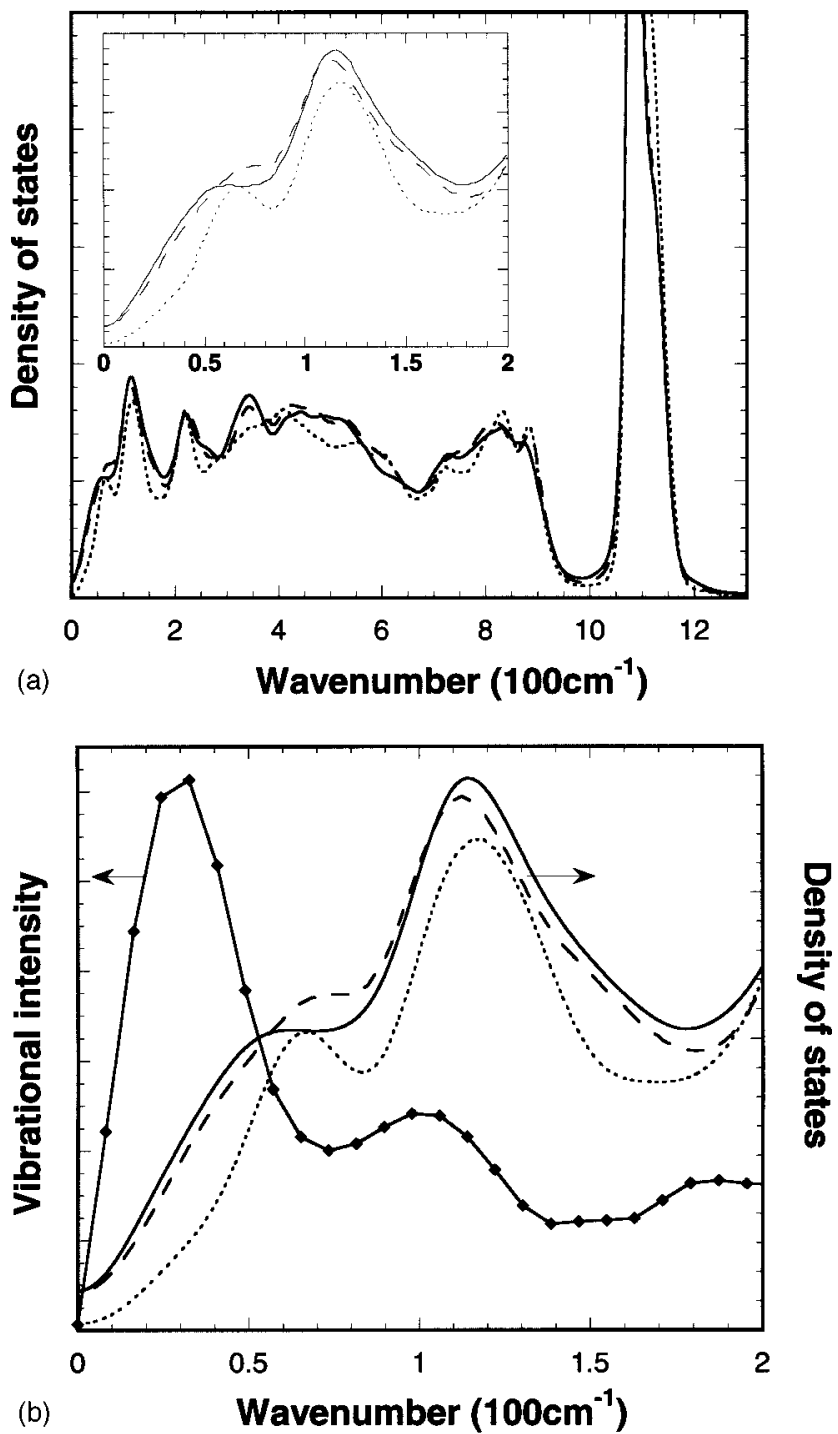

FIG. 11. (a) Density of states (DOS) for $\alpha$-cristobalite at $1000 \mathrm{~K}$ (dotted line), $\beta$-cristobalite at $1200 \mathrm{~K}$ (dashed line) and $1600 \mathrm{~K}$ (solid line), Inset: magnification of the low-frequency range; (b) Frequency spectrum of Si$\mathrm{O}-\mathrm{Si}$ plane oscillations in $\beta$-cristobalite at $1200 \mathrm{~K}$ superimposed onto the low-frequency DOS.

Bourora and Richet showed that after a smooth increase up to $1300 \mathrm{~K}$, the volume of $\beta$-cristobalite decreased continuously up to the melting temperature of $2000 \mathrm{~K}^{15}$ In their subsequent $\mathrm{MD}$ simulations ${ }^{19}$ with rigid-ion potential model derived by Kramer et al. (KFBS) ${ }^{26}$ and in the recent MD study by Yamahara $(2001),{ }^{56}$ the unit cell contraction of $\beta$-cristobalite at high temperature has been attributed to the decrease of the first $\mathrm{Si}-\mathrm{Si}$ distance. In our MD simulations, $\alpha$-cristobalite exhibits positive thermal expansion, while it is nearly zero for $\beta$-cristobalite up to $2000 \mathrm{~K}$ and slightly negative at higher temperatures [Fig. 6(a)]. However, we observe no decrease with temperature in the first neighbor $\mathrm{Si}-\mathrm{Si}$ distance, as seen in Figs. 5 and 6. The $\mathrm{Si}-\mathrm{O}$ bond length increases throughout the simulated temperature range due to the anharmonicity in the interatomic potential. This contributes positively to the thermal expansion. The analysis of $\mathrm{Si}-$ $\mathrm{O}-\mathrm{Si}$ plane normal correlations reveals that with increasing temperature above the $\alpha$ - to $\beta$-cristobalite transformation, cristobalite tends to spend more and more time in $\alpha_{1}$ - and $\alpha_{2}$ states, which are symmetric with respect to the $\beta$-cristobalite configuration. On a time and ensemble average, the orientation of $\mathrm{Si}-\mathrm{O}-\mathrm{Si}$ bonds in the high-temperature phase, and therefore the symmetry of the structure as probed by x rays, corresponds to that of $\beta$-cristobalite. The volume occupied by this structure, however, is determined by the instantaneous distribution of plane orientations. Hence, any local deviation from $\beta$-towards $\alpha$-character will therefore contribute negatively to the thermal expansion, as $\alpha$-cristobalite has a higher density than $\beta$-cristobalite. The Fourier transform of the $\mathrm{Si}-\mathrm{O}-\mathrm{Si}$ plane normal correlation function yields the frequency spectrum of the modes of motion that underlie the $\alpha$-to- $\beta$ transformation, as well as the $\alpha_{1}$-to- $\alpha_{2}$ dynamic disorder of the $\beta$-phase. It turns out that the frequency band of this $\mathrm{Si}-\mathrm{O}-\mathrm{Si}$ plane rotation coincides with the range in the density of states that increases in intensity with increasing temperature as shown in Fig. 11(b). Hence, the same mechanism that facilitates the $\alpha$-to- $\beta$ transformation in cristobalite, and that is responsible for the dynamic disorder in the $\beta$-phase, seems to also bring about the negative thermal expansion in cristobalite at very high temperatures. It has been proposed that negative thermal expansion of $\beta$-cristobalite is due to a reduction of the $\mathrm{Si}-\mathrm{O}-\mathrm{Si}$ angle, thereby bringing nearest-neighbor silicons closer to each other and compacting the structure. ${ }^{19,56}$ While we do observe a slight decrease in the $\mathrm{Si}-\mathrm{O}-\mathrm{Si}$ angle, as shown in Fig. 6(c), the $\mathrm{Si}-\mathrm{Si}$ distance, in fact, does not decrease. As can be seen in Fig. 6(d), the angle decreases because the bridging oxygen moves away from the line connecting the two silicons it is bonded to. All interatomic distances within this triplet of atoms increases, and thus the $\mathrm{Si}-\mathrm{O}-\mathrm{Si}$ angle reduction is not the reason for negative thermal expansion of $\beta$-cristobalite.

\section{CONCLUSIONS}

We have further refined our model for describing interactions in mixed covalent-ionic bonding, by explicitly accounting for charge transfer upon breaking and forming chemical bonds. This development was motivated and justified by the ability to better describe the thermally induced $\alpha$ to $\beta$-cristobalite transformation and the properties of the high-temperature phase. The reliability of this interaction potential is further validated by the excellent agreements between the MD simulated and experimental midinfrared spectra and the density of states, across the $\alpha$ - to $\beta$-cristobalite phase transformation. We believe that our charge transfer potential model is expandable to other $\mathrm{SiO}_{2}$ polymorphs. MD study of quartz with the same potential model is currently underway.

Our MD simulations clarify the nature of the dynamical disorder in $\beta$-cristobalite at high temperatures and confirm that this structure is not made up of static domains of the low-temperature phase. When $\alpha$-cristobalite transforms into $\beta$-cristobalite, whether thermally or pressure induced, the $\mathrm{Si}-\mathrm{O}-\mathrm{Si}$ plane unambiguously rotates by $90^{\circ}$. However, at higher temperatures, the $\mathrm{Si}-\mathrm{O}-\mathrm{Si}$ plane in $\beta$-cristobalite does not remain steady at the characteristic orientation perpendicular to that in $\alpha$-cristobalite, because of the large amount of thermal energy that is absorbed in the mode of 
motion that underlies the transformation between $\alpha$ - and $\beta$-cristobalite. Activation of this $\mathrm{Si}-\mathrm{O}-\mathrm{Si}$ plane rotation mode is also responsible for the nearly zero or even slightly negative thermal expansion of $\beta$-cristobalite. The temporary and local reversal of the structure towards the denser $\alpha$-phase counteracts the positive thermal expansion due to potential anharmonicity, and eventually prevails. In amorphous silica, a similar mechanism is responsible for the increase in elastic modulus with increasing temperature, as will be reported elsewhere.

\section{ACKNOWLEDGMENT}

This work is supported by National Institute of Science and Technology, under Grant No. 60NANB9D0102 and the National Science Foundation under Grant No. DMR0072258 .

${ }^{1}$ G. L. Hua, T. R. Welberry, R. L. Withers, and J. G. Thompson, J. Appl. Crystallogr. 21, 458 (1988).

${ }^{2}$ T. R. Welberry, G. L. Hua, and R. L. Withers, J. Appl. Crystallogr. 22, 87 (1989).

${ }^{3}$ R. L. Withers, J. G. Thompson, and T. R. Welberry, Phys. Chem. Miner. 16, 517 (1989).

${ }^{4}$ D. M. Hatch and S. Ghose, Phys. Chem. Miner. 17, 554 (1991).

${ }^{5}$ R. Spearing, I. Farnan, and J. F. Stebbins, Phys. Chem. Miner. 19, 307 (1992).

${ }^{6}$ W. W. Schmahl, I. P. Swainson, M. T. Dove, and A. Graeme-Barber, Z. Kristallogr. 201, 125 (1992)

${ }^{7}$ I. P. Swainson and M. T. Dove, Phys. Rev. Lett. 71, 193 (1993).

${ }^{8}$ F. Liu, S. H. Garofalini, R. D. King-Smith, and D. Vanderbilt, Phys. Rev. Lett. 70, 750 (1993)

${ }^{9}$ B. L. Phillips, J. G. Thompson, Y. Xia, and R. J. Kirkpatrick, Phys. Chem. Miner. 20, 341 (1993).

${ }^{10}$ I. P. Swainson and M. T. Dove, Phys. Rev. Lett. 71, 193 (1993).

${ }^{11}$ I. P. Swainson and M. T. Dove, Phys. Chem. Miner. 22, 61 (1995).

${ }^{12}$ I. P. Swainson and M. T. Dove, J. Phys.: Condens. Matter 7, 1771 (1995).

${ }^{13}$ M. T. Dove, D. A. Keen, A. C. Hannon, and I. P. Swainson, Phys. Chem. Miner. 24, 311 (1997)

${ }^{14}$ L. Duffrène and J. Kieffer, J. Phys. Chem. Solids 59, 1025 (1998)

${ }^{15}$ E. Bourova and P. Richet, Geophys. Res. Lett. 25, 2333 (1998).

${ }^{16}$ M. Gambhir, M. T. Dove, and V. Heine, Phys. Chem. Miner. 26, 484 (1999).

${ }^{17}$ P. Richet and B. Mysen, Geophys. Res. Lett. 26, 2283 (1999).

${ }^{18}$ D. A. Keen and M. T. Dove, J. Phys.: Condens. Matter 11, 9263 (1999).

${ }^{19}$ E. Bourova, S. C. Parker, and P. Richet, Phys. Rev. B 62, 12052 (2000).

${ }^{20}$ M. G. Tucker, M. P. Squires, M. T. Dove, and D. A. Keen, J. Phys.: Condens. Matter 13, 403 (2001).

${ }^{21}$ R. W. G. Wyckoff, Am. J. Sci. 209, 448 (1925).

${ }^{22}$ A. F. Wright and A. J. Leadbetter, Philos. Mag. 31, 1391 (1975).

${ }^{23}$ D. C. Allan and M. P. Teter, Phys. Rev. Lett. 59, 1136 (1987).

${ }^{24}$ J. Chelikowsky, N. Troullier, J. L. Martins, and H. E. King, Phys. Rev. B 44, 489 (1991)

${ }^{25}$ R. A. Jackson and C. R. A. Catlow, Mol. Simul. 1, 207 (1988).
${ }^{26}$ G. J. Kramer, N. P. Farragher, B. W. H. van Beest, and R. A. van Santen, Phys. Rev. B 43, 5068 (1991)

${ }^{27}$ K. de Boer, A. P. J. Jansen, and R. A. van Santen, Chem. Phys. Lett. 223, 46 (1994).

${ }^{28}$ A. C. Lasaga and G. V. Gibbs, Phys. Chem. Miner. 16, 28 (1988).

${ }^{29}$ A. C. Lasaga and G. V. Gibbs, Phys. Chem. Miner. 14, 107 (1987).

${ }^{30}$ S. Tsuneyuki, M. Tsukada, H. Aoki, and Y. Matsui, Phys. Rev. Lett. 61, 869 (1988).

${ }^{31}$ B. W. H. van Beest, G. J. Kramer, and R. A. van Santen, Phys. Rev. Lett. 64, 1955 (1990).

${ }^{32}$ N. R. Keskar and J. R. Chelikowky, Phys. Rev. B 46, 1 (1992).

${ }^{33}$ M. J. Sander, M. Leslie, and C. R. A. Catlow, J. Chem. Soc. Chem. Commun. 19, 1271 (1984).

${ }^{34}$ R. L. Erikson and C. J. Hostetler, Geochim. Cosmochim. Acta 51, 1209 (1987).

${ }^{35}$ S. Tsuneyuki, Y. Matsui, H. Aoki, and M. Tsukada, Nature (London) 339, 209 (1989).

${ }^{36}$ S. Tsuneyuki, H. Aoki, M. Tsukada, and Y. Matsui, Phys. Rev. Lett. 64, 776 (1990).

${ }^{37}$ J. R. Rustad, D. A. Yuen, and F. J. Spera, Phys. Rev. A 42, 2081 (1990).

${ }^{38}$ J. R. Chelikowsky, H. E. J. King, and J. Glinnemann, Phys. Rev. B 41, 10866 (1990).

${ }^{39}$ R. G. Guido, D. Vella, and H. C. Andersen, J. Chem. Phys. 94, 5056 (1991).

${ }^{40}$ S. T. John and D. K. Dennis, J. Chem. Phys. 95, 9176 (1991)

${ }^{41}$ P. Vashishta, R. K. Kalia, and J. P. Rino, Phys. Rev. B 41, 12197 (1989).

${ }^{42}$ B. P. Feuston and S. H. Garofalini, J. Chem. Phys. 89, 5818 (1988).

${ }^{43}$ C. R. A. Catlow and A. N. Cormack, Int. Rev. Phys. Chem. 6, 227 (1987).

${ }^{44}$ M. L. Huggins and J. E. Mayer, J. Chem. Phys. 1, 643 (1933).

${ }^{45}$ P. P. Ewald, Ann. Phys. (Leipzig) 64, 253 (1921).

${ }^{46}$ C. Kittel, Introduction to Solid State Physics (Wiley, New York, 1996).

${ }^{47}$ T. Hahn, International Tables for Crystallography (Reidel, Dordrecht, 1984).

${ }^{48}$ J. J. Pluth, J. V. Smith, and J. Faber, J. Appl. Phys. 57, 1045 (1985).

${ }^{49}$ H. C. Andersen, J. Chem. Phys. 72, 2384 (1980).

${ }^{50}$ M. Parrinello and A. Rahman, J. Appl. Phys. 52, 7182 (1981).

${ }^{51}$ S. Nose, J. Chem. Phys. 81, 511 (1984).

${ }^{52}$ K. L. Klein, Molecular Dynamics Simulation of Statistical Mechanical Systems (North-Holland, Amsterdam, 1986).

${ }^{53}$ M. T. Dove, Introduction to Lattice Dynamics (Cambridge University Press, Cambridge, 1993).

${ }^{54}$ P. H. Berens and K. R. Wilson, J. Chem. Phys. 74, 4872 (1981).

${ }^{55}$ D. C. Anderson, J. Kieffer, and S. Klarsfeld, J. Chem. Phys. 98, 8978 (1993).

${ }^{56}$ K. Yamahara, K. Okazaki, and K. Kawamura, J. Non-Cryst. Solids 291, 32 (2001).

${ }^{57}$ M. T. Dove, A. P. Giddy, and V. Heine, Trans. Am. Crystallogr. Assoc. 27, 65 (1993).

${ }^{58}$ M. G. Tucker, M. T. Dove, and D. A. Keen, J. Phys.: Condens. Matter 12, L723 (2000).

${ }^{59}$ K. S. Finnie, J. G. Thompson, and R. L. Withers, J. Phys. Chem. Solids 55(1), 23 (1994).

${ }^{60}$ E. K. H. Salje, Phase Transitions 37, 83 (1992).

${ }^{61}$ G. L. Hua, T. R. Welberry, R. L. Withers, and J. G. Thompson, J. Appl. Crystallogr. 21, 458 (1988).

${ }^{62}$ G. Dolino, B. Berge, M. Vallade, and F. Moussa, J. Phys. (Paris) 2, 1461 (1992).

${ }^{63}$ F. Amuento, Am. Mineral. 51, 1176 (1966). 